\title{
Carta de Santa Cruz, EMMP (2015)
}

Encuentro Mundial de los Movimientos Populares (EMMP)

Las organizaciones sociales reunidas en el Segundo Encuentro Mundial de Movimientos Populares, en Santa Cruz de la Sierra, Bolivia, durante los días 7, 8 y 9 de julio de 2015, coincidimos con el Papa Francisco en que la problemática social y ambiental emergen como dos caras de la misma moneda. Un sistema que no puede brindar tierra, techo y trabajo para todos, que socava la paz entre las personas y amenaza la propia subsistencia de la Madre Tierra, no puede seguir rigiendo el destino del planeta.

Debemos superar un modelo social, político, económico y cultural donde el mercado y el dinero se han convertido en el eje regulador de las relaciones humanas en todos los niveles.

Nuestro grito, el de los más postergados y marginados, obliga a que los poderosos comprendan que así, no se puede seguir. Los pobres del mundo se han levantado contra la exclusión social que sufren día a día. No queremos explotar ni ser explotados. No queremos excluir ni ser excluidos. Queremos construir un modo de vida en el que la dignidad se alce por encima de todas las cosas.

Por eso, nos comprometemos a:

\section{IMPULSAR Y PROFUNDIZAR EL PROCESO DE CAMBIO}

Reafirmamos nuestro compromiso con los procesos de cambio y liberación como resultado de la acción de los pueblos organizados, que desde su memoria colectiva toman la historia en sus manos y se 
deciden a transformarla, para dar vida a las esperanzas y las utopías que nos convocan a revolucionar las estructuras más profundas de opresión, dominación, colonización y explotación.

\section{VIVIR BIEN EN ARMONÍA CON LA MADRE TIERRA}

Seguiremos luchando para defender y proteger a la Madre Tierra, promoviendo la "ecología integral" de la que habla el Papa Francisco. Somos fieles a la filosofía ancestral del "Vivir Bien", nuevo orden de vida que propone armonía y equilibrio en las relaciones entre los seres humanos y entre éstos y la naturaleza.

La tierra no nos pertenece, nosotros pertenecemos a la tierra. Debemos cuidarla y labrarla en beneficio de todos. Queremos leyes medioambientales en todos los países en función del cuidado de los bienes comunes.

Exigimos la reparación histórica y un marco jurídico que resguarde los derechos de los pueblos indígenas a nivel nacional e internacional, promoviendo un diálogo sincero a fin de superar los diversos y múltiples conflictos que atraviesan los pueblos indígenas, originarios, campesinos y afrodescendientes.

\section{DEFENDER EL TRABAJO DIGNO}

Nos comprometemos a luchar por la defensa del trabajo como derecho humano. Por la creación de fuentes de trabajo digno, por el diseño e implementación de políticas que restituyan todos los derechos laborales eliminados por el capitalismo neoliberal, tales como los sistemas de seguridad social, de jubilación y el derecho a la sindicalización.

Rechazamos la precarización, la tercerización y buscamos que se supere la informalidad a través de la inclusión, nunca con persecución ni represión.

Asimismo, levantamos la causa de los migrantes, desplazados y refugiados. Instamos a los gobiernos de los países ricos a que deroguen todas aquellas normas que promueven un trato discriminatorio contra 
ellos y establezcan formas de regulación que eliminen el trabajo esclavo, la trata, el tráfico de personas y la explotación infantil.

Impulsaremos formas alternativas de economía, tanto en áreas urbanas como en zonas rurales. Queremos una economía popular y social comunitaria que resguarde la vida de las comunidades y en la que prevalezca la solidaridad por sobre el lucro. Para esto es necesario que los gobiernos fortalezcan los esfuerzos que emergen de las bases sociales.

\section{MEJORAR NUESTROS BARRIOS Y CONSTRUIR VIVIENDAS DIGNAS}

Denunciamos la especulación y mercantilización de los terrenos y los bienes urbanos. Rechazamos los desalojos forzosos, el éxodo rural y el crecimiento de los barrios marginados. Rechazamos cualquier tipo de persecución judicial contra quienes luchan por una casa para su familia, porque entendemos a la vivienda como un derecho humano básico, el cual debe ser de carácter universal.

Exigimos políticas públicas participativas que garanticen el derecho a la vivienda, la integración urbana de los barrios marginados y el acceso integral al hábitat para edificar hogares con seguridad y dignidad.

\section{DEFENDER LA TIERRA Y LA SOBERANÍA ALIMENTARIA}

Promovemos la reforma agraria integral para distribuir la tierra de manera justa y equitativa. Llamamos la atención de los pueblos sobre el surgimiento de nuevas formas de acumulación y especulación de la tierra y el territorio como mercancía, vinculadas al agro-negocio, que promueve el monocultivo destruyendo la biodiversidad, consumiendo y contaminando el agua, desplazando poblaciones campesinas y utilizando agro-tóxicos que contaminan los alimentos.

Reafirmamos nuestra lucha por la eliminación definitiva del hambre, la defensa de la soberanía alimentaria y la producción de alimentos sanos. Asimismo rechazamos enfáticamente la propiedad privada de semillas 
por grandes grupos agroindustriales, así como la introducción de productos transgénicos en sustitución de los nativos, debido a que destruyen la reproducción de la vida y la biodiversidad, crean dependencia alimentaria y causan efectos irreversibles sobre la salud humana y el medio ambiente. De igual manera, reafirmamos la defensa de los conocimientos tradicionales de los pueblos indígenas sobre la agricultura sustentable.

\section{CONSTRUIR LA PAZ Y LA CULTURA DEL ENCUENTRO}

Nos comprometemos, desde la vocación pacífica de nuestros pueblos a intensificar las acciones colectivas que garanticen la paz entre todas las personas, pueblos, religiones, etnias y culturas.

Reafirmamos la pluralidad de nuestras identidades culturales y tradiciones que deben convivir armónicamente sin que unas sometan a otras. Nos levantamos en contra de la criminalización de nuestra lucha, pues están criminalizando nuestras costumbres.

Condenamos cualquier tipo de agresión militar y nos movilizamos por el cese inmediato de todas las guerras y de las acciones desestabilizadoras o golpes de Estado, que atentan contra la democracia y la elección de los pueblos libres. Rechazamos el imperialismo y las nuevas formas de colonialismo, sean militares, financieras o mediáticas. Nos pronunciamos contra la impunidad de los poderosos y a favor de la libertad de los luchadores sociales.

\section{COMBATIR LA DISCRIMINACIÓN}

Nos comprometemos a luchar contra cualquier forma de discriminación entre los seres humanos, sea por diferencias étnicas, color de la piel, género, origen, edad, religión u orientación sexual. Todos nosotros, mujeres y hombres, debemos tener los mismos derechos. Condenamos el machismo, cualquier forma de violencia contra la mujer, en particular los femicidios, y gritamos ¡Ni una menos!. 


\section{PROMOVER LA LIBERTAD DE EXPRESIÓN}

Promovemos el desarrollo de medios de comunicación alternativos, populares y comunitarios, frente al avance de los monopolios mediáticos que ocultan la verdad. El acceso a la información y la libertad de expresión son derechos de los pueblos y fundamento de cualquier sociedad que se pretenda democrática, libre y soberana.

La protesta es también una legítima forma de expresión popular. Es un derecho y quienes lo ejercemos no debemos ser perseguidos por ello.

\section{PONER LA CIENCIA Y TECNOLOGÍA AL SERVICIO DE LOS PUEBLOS}

Nos comprometemos a luchar para que la ciencia y el conocimiento sean utilizados al servicio del bienestar de los pueblos. Ciencia y conocimiento son conquistas de toda la humanidad y no pueden estar al servicio de la ganancia, explotación, manipulación o acumulación de riquezas por parte de algunos grupos. Persuadimos a que las universidades se llenen de pueblo y sus conocimientos estén orientados a resolver los problemas estructurales más que a generar riquezas para las grandes corporaciones. A denunciar y controlar a las multinacionales farmacéuticas que por un lado, lucran con la expropiación de conocimientos milenarios de los pueblos originarios y, por el otro, especulan y generan ganancias con la salud de millones de personas, poniendo el negocio por delante de la vida.

\section{RECHAZAMOS EL CONSUMISMO Y DEFENDE- MOS LA SOLIDARIDAD COMO PROYECTO DE VIDA}

Defendemos la solidaridad como proyecto de vida personal y colectivo. Nos comprometemos a luchar contra el individualismo, la ambición, la envidia y la codicia que anidan en nuestras sociedades y muchas veces en nosotros mismos. Trabajaremos incansablemente para erradicar el consumismo y la cultura del descarte.

Seguiremos trabajando para construir puentes entre los pueblos, que nos permitan derribar los muros de la exclusión y la explotación! 